\title{
ASSESSING KNOWLEDGE, PERCEPTION AND ATTITUDES ABOUT ANTIBIOTICS AMONG FINAL YEAR PHARMACY UNDERGRADUATES IN SRI LANKA
}

\author{
SHUKRY ZAWAHIR ${ }^{a}$, CHATHURANGANI HETTIARACHCHI ${ }^{b}$, HANA MORRISSEYc
}

aFaculty of Pharmacy, University of Sydney, NSW, Australia, bFaculty of Medicine, University of Ruhuna, Galle, Sri Lanka, cSchool of Pharmacy, Faculty of Science and Engineering, University of Wolverhampton

Email: hana.morrissey@wlv.ac.uk

Received: 08 Aug 2017 Revised and Accepted: 21 Sep 2017

\begin{abstract}
Objective: Anti-microbial resistance has become a global problem especially in developing countries. The aim of the study was to evaluate the effect of socio-demographic predictors amongst final year pharmacy undergraduates in Sri Lanka on their knowledge, perception and attitudes regarding
\end{abstract} antibiotic use.

Methods: A questionnaire-based study involved final year pharmacy students from four public universities in Sri Lanka. Data on knowledge, attitudes and perception about the appropriate use of antibiotics were analysed. Ethics approval was granted by the university of Ruhuna Sri Lanka.

Results: There was good general knowledge of antibiotics (mean=15.57), however, 46\% said metronidazole is not an antibiotic, $82 \%$ said that the use of antibiotics speed-up the recovery from the common cold. Perception $(p=0.033)$ and attitudes $(p=0.028)$ of respondents from urban area were significantly higher than that of those from rural area.

Conclusion: Clinical education for pharmacy undergraduates should have an in-depth focus on the rational of antibiotics use in Sri Lanka.

Keywords: Antibiotics, Knowledge, Attitudes, Perception, Sri Lanka, Pharmacy students

(C) 2017 The Authors. Published by Innovare Academic Sciences Pvt Ltd. This is an open access article under the CC BY license (http://creativecommons.org/licenses/by/4.0/) DOI: http://dx.doi.org/10.22159/ijpps.2017v9i11.21891

\section{INTRODUCTION}

Antimicrobial agents have been used to treat patients who have infectious diseases over the last $70 \mathrm{y}$. Since the $1940 \mathrm{~s}$, these medications have reduced morbidity and mortality related to infectious diseases, saving countless lives through scientific discoveries [1]. However, these achievements are now threatened by the global emergence of resistant strains [2] and the inability of the industry to introduce new antibiotics [3].

Antibiotics are among the most commonly prescribed, sold and used drugs globally $[4,5]$. Their use could be either appropriate or inappropriate, the use has been viewed as a key driver for progressive loss of bacterial sensitivity to antibiotics and the emergence, increase and spread of antibiotic resistance (ABR) $[4,5]$. The emergence and spread of microbial resistance to antibiotics is an important global public health issue that has been linked to the inappropriate use of antibiotics worldwide [6-8]. This is known to contribute to therapeutic failure when treating infections, due to presence of antibiotic-resistant micro-organisms. This leads to longer hospital stays, and increased mortality and health-care costs [2, 9-11].

The ABR crisis impacts more in developing countries, (especially in low socioeconomics countries) because of high burden of infectious diseases $[1,12]$. This may be compounded by irrational practices of prescribing antibiotics mainly for upper respiratory infections [13-16], and immature antibiotics stewardship policies. This may be complicated by the availability of antibiotics without prescription (regulated but not controlled) [17-19] and lack of laboratories for antibiotics susceptibility testing and surveillance. Factors such as; lack of access to health care services, services are not affordable, limited regulatory control of the use of prescription medicines including antibiotics, limited understanding of the role of antibiotics, the opportunity to self-medicate, the concern of doctors for the risk of secondary bacterial infections after viral illnesses in poor environments, prohibitive cost sensitivity testing and pharmaceutical promotional tactics all compound the problem [20-22].

In many countries where antibiotics are 'prescription only medicines,' they are in practice widely available 'over the counter,' especially in developing and resource limited countries. A 'prescription only' drug such as tetracycline could be obtained easily from pharmacies without prescription in the capital city of Sri Lanka [23]. Though antibiotics are not indicated for acute diarrhoea, they are widely supplied without prescription in Sri Lanka, Bangladesh and Yemen [24].

The measures required to slow the development and transmission of resistant microorganisms are used internationally for infection control and microbial surveillance to decrease the global burden of infectious diseases and control the use of antibiotics [25]. Pivotal to these measures are changing antibiotic use and public and professional attitudes and require all parties including physicians, pharmacists and consumers to be better informed about the dangers of inappropriate use [25].

In Sri Lanka, dispensing any prescription medicines, including antibiotics, without a valid prescriptions is prohibited by law [26], yet it is common knowledge that pharmacies often sell restricted medicines to clients who seek medical care, either based upon their expressed symptoms or on specific product requests [27]. Although every pharmacy is legally required to have a registered pharmacist, in many instances, an assistant pharmacist is operating the store without a pharmacist in attendance. These assistants generally have only a few years of school education and seldom has received any formal pharmacy education or training [23].

Pharmacy practice in Sri Lanka is behind that in developed and in some other developing countries. Dispensing is the core business of pharmacists in Sri Lanka in both community and hospital pharmacy settings. The majority of hospital pharmacists have a pharmacy proficiency qualification; this is a two-year formal pharmacy education in a certificate program with the internship in the public hospitals. Conversely community pharmacists are mostly trained through apprenticeships with external community pharmacy training (efficiency pharmacy qualification) and are registered with the Sri Lanka medical council as a pharmacist [28]. There are very few University graduate pharmacists, and they work mainly in the formulation and production areas, public and private hospitals or drug 
regulatory authorities in Sri Lanka. Since 2005, public universities in Sri Lanka have started to offer a number of bachelor of pharmacy (B Pharm) undergraduate degrees [26], with the first candidates having graduated in 2009. Now, pharmacy practice is slowly gaining recognition in the local health services. The concept of this study was developed to evaluate the knowledge and competency of B Pharm graduates (future pharmacists) in aspects of clinical practice of pharmacy in both community and hospital pharmacy settings.

To date, no study has been published on the knowledge, attitude and perception of the use of antibiotics among final year pharmacy undergraduates in Sri Lanka. This aim of this study was to establish a starting point for the knowledge, perception and attitudes regarding antibiotic use in Sri Lankan final year pharmacy undergraduates.

\section{MATERIALS AND METHODS}

\section{Study design}

A cross-sectional study was carried out among final year pharmacy students at four out of five universities in Sri Lanka offering this course.

\section{Setting}

The survey encompassed final year pharmacy undergraduates at the University of Ruhuna, University of Colombo, University of Sri Jayewardenepura and the University of Jaffna. All the above universities offering BPharm program except the University of Colombo, which offers a Bachelor of Science (Pharmacy) degree.

\section{Population}

The total study population was 79 final year pharmacy students with 30 students from the University of Ruhuna, 25 students from the University Sri Jayawardenapura, 12 students from the University of Colombo and 12 students from the University of Jaffna. All the eligible students had given consent; hence the response rate was $100 \%$.

\section{Method}

The study instrument was a self-administered questionnaire. This was adopted from previous studies that have already undergone a face validation and content validation process [29-31]. The original questionnaire was written in English, which is the approved language of study for pharmacy degrees in Sri Lanka. The questionnaire consisted of four sections. The first section explored demographic information; gender, family background, family residence, parents' level of education and ethnicity. The second section comprised of 9 questions, evaluating the participants' knowledge regarding antibiotics and their use (table 2). The third part explored perceptions on antibiotics use and resistance among the participants which included 8 questions (table 3). The fourth section assessed the attitude of participants regarding antibiotics and this section included four questions (table 4).

A common scoring standard was used for each question in all the three categories, knowledge, perception and attitudes. The answers were deemed as 'correct' or 'wrong' for the single-answer questions generally considering whether it corresponded with the prevailing evidence. Value of 1 or 0 points were assigned to the 'correct' or 'wrong' answers, respectively. The score was then summed to give a total between $0-14$ for the knowledge of participants, $0-10$ for their perceptions and 0-4 for their attitudes regarding antibiotics. Each of these summed variables were treated as a continuous outcome variable as all of them were showing a normal distribution pattern in the preliminary analysis.

The Universities were assigned a code as A, B, C and D for Colombo, Jayewardenepura, Jaffna and Ruhuna respectively.

\section{Inclusion criteria}

The pharmacy undergraduate who were (1) in final year of their undergraduate pharmacy course and (2) gave written informed consent to participate in the study.

\section{Data analysis}

Statistical analysis was conducted using SPSS ${ }^{\text {TM }} 20$ (IBM Armonk, NY, USA) statistical software. Descriptive statistics results were expressed as mean $\pm \mathrm{SD}$ (standard deviation) and frequencies (percentages). Assessment of difference between demographic characteristics of the participants and their knowledge, perception and attitudes were carried out using independent $t$ test and one-way ANOVA and whenever appropriate post hoc Bonferroni's multiple comparison test was also conducted. A Pearson product-moment correlation coefficient test was computed to assess the relationship among the all three outcome variables. In all cases, $\mathrm{p}$ values $<.05$ were taken as statistically significant.

\section{Ethical approval}

The study was conducted after obtaining ethical approval (Reference No: 31.03.2015.03.10) from the ethical review committee, faculty of medicine, University of Ruhuna Sri Lanka. Written permission also obtained from heads of the respective departments or faculties of the four universities prior to the data collection.

\section{Consent and data collection}

The data collection was carried out by one of the researchers visiting each respective university between July and October 2015. After explaining the purpose of the study, voluntary participation and the confidentiality of the data, and confirming that every participant was clearly informed about the study, written consent was obtained from all participants. The time burden was approximately 10-15 min to complete the questionnaire.

\section{RESULTS}

\section{Socio demographic characteristics of participants}

Table 1 shows the descriptive statistics of the socio-demographic characteristics of participants. Out of the total 79 students who participated in this study, $38 \%$ were from the University of Ruhuna followed by $31.6 \%$ from University of Sri Jayewardenepura and $15.2 \%$ each from the of University of Jaffna and University of Colombo. All the participants were final year pharmacy students. More than half of the participants were females $(\mathrm{N}=52,65.8 \%)$. Slightly more than half of the participants were from an urban area (51.9\%). For most participants, their parents highest level of education was until advanced level (Year 13) $(\mathrm{N}=53,67 \%)$ and almost all their parents $(\mathrm{N}=75,94.9 \%)$ had education other than in health-related fields. Regarding ethnicity $84.8 \%(\mathrm{~N}=67)$ of the participants identified as Sinhalese, $8.9 \%$ as Tamil and $6.3 \%$ as Muslim.

\section{Knowledge about antibiotics}

Table 2 describes the knowledge regarding antibiotics. The results reveal good basic knowledge but some concerning findings (Mean $=12.08 \mathrm{SD}=0.89$ ). A considerable number mentioned that antibiotics can cure viral infections (9\%) and many suggested that antibiotics will speed up the recovery of cold and cough (82\%). About $11.4 \%$ of the participants believed that frequent use of antibiotics will not decrease the efficacy the treatment when using the antibiotics again. Some of the participants said that newer and higher price antibiotics are better $(32 \%)$. Regrettably almost half $(46 \%)$ of the future pharmacists (final year pharmacy students) said that metronidazole is not an antibiotic.

As determined by one-way ANOVA there was no statistically significant difference on mean knowledge about antibiotics among final year pharmacy students of different universities $(F(3,75)=$ $0.597, p=.619)$, different level of parents' education $F(2,76)=$ $0.147, p=.863$ ) and the ethnicity $F(2,76)=0.260, p=.772$ ) (where $F$ is the F-statistics and $p$ is probability).

A Bonferroni post-hoc test also confirmed no significant difference $(p>0.05)$.

An independent-samples t-test was conducted to compare mean knowledge in males and females; rural and urban; parent's occupation related to the medical field of participants. These results suggest that these predictors do not have an effect on pharmacy students' knowledge about antibiotics. 
Table 1: Socio demographic characteristics of participants

\begin{tabular}{|c|c|}
\hline Variable & Frequency (\%) \\
\hline Name of the university & $\mathrm{N}=79$ \\
\hline A & $12(15.2)$ \\
\hline B & $12(15.2)$ \\
\hline $\mathrm{C}$ & $30(38.0)$ \\
\hline $\mathrm{D}$ & 25 (31.6) \\
\hline Academic year & $\mathrm{N}=79$ \\
\hline $4^{\text {thY Year }}$ & $79(100.0)$ \\
\hline Gender & $\mathrm{N}=79$ \\
\hline Male & $27(34.2)$ \\
\hline Female & $52(65.8)$ \\
\hline Family residence & $\mathrm{N}=79$ \\
\hline Urban & $41(51.9)$ \\
\hline Rural & $38(48.1)$ \\
\hline Parent' Education & $\mathrm{N}=79$ \\
\hline Up to $0 / 1$ & $12(15.2)$ \\
\hline Up to $A / 1$ & 41 (51.9) \\
\hline High Education & $26(32.9)$ \\
\hline Parent' Occupation & $\mathrm{N}=79$ \\
\hline Related to medical field & $4(5.1)$ \\
\hline Not related to medical field & $75(94.9)$ \\
\hline Ethnicity & $\mathrm{N}=79$ \\
\hline Sinhalese & $67(84.8)$ \\
\hline Tamil & $7(8.9)$ \\
\hline Muslim & $5(6.3)$ \\
\hline
\end{tabular}

$\mathrm{N}=$ Number of participants

Table 2: Knowledge on antibiotics among pharmacy undergraduates in Sri Lanka

\begin{tabular}{ll}
\hline Variables & Frequency (\%) \\
\hline Are there bacteria in human body which are good for our health? & $\mathrm{N}=79$ \\
Yes & $77(97.5)$ \\
Antibiotics can be used to cure infections caused by bacteria. & $\mathrm{N}=79(100.0)$ \\
Yes & $\mathrm{N}=79$ \\
Antibiotics can be used to cure infections caused by viruses. & $8(8.9)$ \\
Yes & $\mathrm{N}=79$ \\
The use of antibiotics will speed up the recovery of common cold. & $65(82.3)$ \\
Yes & $\mathrm{N}=79$ \\
Heard about resistance of bacteria & $78(98.7)$ \\
Yes & $\mathrm{N}=79$ \\
Frequent use of antibiotics may reduce future antibiotic use benefit. & $70(88.6)$ \\
Yes & $\mathrm{N}=79$ \\
Antibiotics are more effective if they are newer and expensive. & $25(31.6)$ \\
Yes & $\mathrm{N}=79$ \\
Which of the following drugs are antibiotics? & $79(100.0)$ \\
Amoxicillin & $\mathrm{N}=79$ \\
Yes & $1(1.3)$ \\
Yes & $\mathrm{N}=79$ \\
Metronidazole & $43(54.4)$ \\
Yes & $\mathrm{N}=79$ \\
Tetracycline & $78(98.7)$ \\
Yes & $\mathrm{N}=79$ \\
Yes & $1(1.3)$ \\
What is "antibiotics susceptibility test" used for? & $\mathrm{N}=79$ \\
To test if the antibiotic is efficient for infections by some bacteria. & $77(97.5)$ \\
To test if the antibiotic is efficient for infections by some viruses. & $2(2.5)$ \\
\hline
\end{tabular}

\section{Perception towards antibiotics use and emergence of resistance}

Descriptive statistics of the students' perceptions are shown in table 3 . The results show clear overall favourable perception among the participants on antibiotic use and resistance (Mean $=8.37 \mathrm{SD}=1.34$ ). Almost all perceived the current existence of antibiotics abuse (92\%) and that it is the main cause of ABR (84\%). They also perceived that ABR is a major health problem in Sri Lanka $(95 \%)$ and it may harm themselves and their family (92\%). They recognized the importance of gaining more information about antibiotics (96\%) and the establishment of university level courses promoting rational use of antibiotics (95\%). They also saw the need for a major campaign to educate the public in Sri Lanka on antibiotic use (77\%). Participants believe the one of the major root causes of antibiotics abuse is that the drug manufacturers, hospitals, and other sectors are driven by economic interests rather than health benefits of the patients $(81 \%)$.

A one-way ANOVA test revealed that there was no statistically significant difference on mean perception about antibiotics use and resistance among final year pharmacy students of different 
universities $(F(3,75)=0.796, p=0.500)$, different level of parents education $F(2,76)=1.778, p=0.176)$ and the ethnicity $F(2,76)=$ $0.170, p=.844$ ). Again a Bonferroni post hoc test confirmed this $(p>0.05)$.
Independent-sample t-test results revealed that there was a significant different in the perception about antibiotic use and resistance between the students from urban $(\mathrm{M}=8.83, \mathrm{SD}=1.05)$ and rural $(\mathrm{M}=7.87, \mathrm{SD}=1.45) ; \mathrm{t}(77)=3.39, \mathrm{p}=0.01$ areas.

Table 3: Perception on antibiotics use and resistance among final year pharmacy students

\begin{tabular}{|c|c|}
\hline Variable & Frequency (\%) \\
\hline I think it is necessary to get more information about antibiotics & $\mathrm{N}=79$ \\
\hline Yes & $76(96.2)$ \\
\hline It is necessary to establish the course "Rational use of antibiotics" at the university level & $\mathrm{N}=79$ \\
\hline Yes & $75(94.9)$ \\
\hline I think, the "antibiotics campaign" is a kind of large-scale science propaganda activity & $\mathrm{N}=79$ \\
\hline Yes & $61(77.2)$ \\
\hline I think there is abuse of the current antibiotics. & $\mathrm{N}=79$ \\
\hline Yes & $73(92.4)$ \\
\hline Bacterial antibiotic resistance is a problem in Sri Lanka. & $\mathrm{N}=79$ \\
\hline Yes & $75(94.9)$ \\
\hline The abuse of antibiotics is the main cause of bacterial resistance. & $\mathrm{N}=79$ \\
\hline Yes & $66(83.5)$ \\
\hline Antibiotic resistance can affect me and my family's health. & $\mathrm{N}=79$ \\
\hline Yes & $73(92.4)$ \\
\hline \multicolumn{2}{|l|}{ Root Cause of antibiotics abuse; } \\
\hline Principles of antibiotic use are not globalised. & $\mathrm{N}=79$ \\
\hline Yes & $46(58.2)$ \\
\hline Drug manufacturers are more driven by economic interests. & $\mathrm{N}=79$ \\
\hline Yes & $64(81.0)$ \\
\hline There are loopholes in the health and medicine regulation. & $\mathrm{N}=79$ \\
\hline Yes & $52(65.8)$ \\
\hline
\end{tabular}

$\mathrm{N}=$ Number of participants

\section{Attitudes about antibiotics use}

Table 4 describes the attitudes of final year pharmacy students in relation to the side effects of antibiotics. The one-way ANOVA test determined no statistically significant difference on mean attitudes about antibiotics score between universities $F(3,75)=$ $1.518, p=.217)$, different level of parents education $F(2,76)=$ $0.501, p=.608$ ) and the ethnicity $F(2,76)=2.919, p=.060)$. Once more a Bonferroni post hoc test confirmed this $(p>0.05)$. Conversely, an independent-samples t-test revealed a statistically significant positive attitude among females $(\mathrm{M}=2.83, \mathrm{SD}=0.83)$ and urban $(\mathrm{M}=2.85, \mathrm{SD}=0.94)$ final year pharmacy students compared to males $(\mathrm{M}=2.30, \mathrm{SD}=0.99) ; \mathrm{t}(77)=2.51, \mathrm{p}=0.014$ and rural $(\mathrm{M}=2.42$, $\mathrm{SD}=0.86) ; \mathrm{t}(77)=2.13, \mathrm{p}=0.036$ students.

There was a significant positive correlation found between variables; overall knowledge about antibiotics and perception on antibiotic use and resistance. Overall perception scores increase in proportion with knowledge-related antibiotics score $(\mathrm{r}=0.22, \mathrm{n}=$ $79, \mathrm{p}=0.047$ ) and vice versa.

Table 4: Attitudes on antibiotics among pharmacy undergraduates in Sri Lanka

\begin{tabular}{|c|c|}
\hline Variable & Frequency (\%) \\
\hline When use antibiotics, I am worried about side effects. & $\mathrm{N}=79$ \\
\hline Agree & $60(75.9)$ \\
\hline I tend to stop using antibiotics when I experience side effects. & $\mathrm{N}=79$ \\
\hline Agree & $32(40.5)$ \\
\hline If antibiotics harm equals their benefit, I prefer not to use them. & $\mathrm{N}=79$ \\
\hline Agree & $51(64.6)$ \\
\hline If I experience side effects when using antibiotics, I will consult a doctor. & $\mathrm{N}=79$ \\
\hline Agree & $66(83.5)$ \\
\hline
\end{tabular}

$\mathrm{N}=$ Number of participants

\section{DISCUSSION}

So far as can be established, this is the first survey conducted in Sri Lanka to demonstrate knowledge, perception and attitudes regarding antibiotics among only final year pharmacy undergraduates. Final year pharmacy undergraduate students are the immediate future pharmacist workforce throughout the Island, so this study provides some insight into their competency to work against $A B R$ and to guide improvements in the curriculum of $B$ Pharm programs in Sri Lanka to specifically focus on antibiotics and their resistance.

The overall knowledge of participants regarding antibiotics was predominantly sound. This suggests the curriculum relating to antibiotics and their use is mostly appropriate. A similar type of study was conducted in China, with medical students. It showed their knowledge improved as they progressed with their study [30]. However, examining individual questions, it is concerning that a majority of the participants ( $82 \%$ ) believed antibiotics will speed up the recovery of coughs and colds. This observation has been reported in a number of studies conducted among undergraduate students of medical sciences and non-medical sciences [5,32]. However, as the majority of upper respiratory tract infections (URTIs) are viral, antibiotics are not indicated [35]. Studies demonstrate that antibiotics can provide only minor benefit, or no benefit for these infections [13-14, 33-35]. The unnecessary use of antibiotics for viral URTIs is claimed to be an important contributors to antibiotic misuse globally [36]. 
Also of concern was that $46 \%$ of the participants failed to identify metronidazole as an antibiotic. This should be also considered as a serious issue as the nation's future pharmacists were unable to recognize one of the commonest antibiotics. Previous studies found a lack of knowledge of pharmacists is one the factors attributed to dispensing malpractices $[37,38]$. As a study conducted in Kuwait showed that public advice on how to use antibiotics primarily comes from pharmacists rather than doctors [39].

The participants perceived that $\mathrm{ABR}$ is a serious health problem in Sri Lanka and believed that inappropriate use is one of the main causes. This in line with a Portuguese study that reported patients' non-compliance with prescribed dosage to be one cause of ABR [40]. Other factors such as the economic interests of drug manufacturers, hospitals and other sectors, and loopholes in the regulation are the identified by the participants as contributors to ABR in Sri Lanka. Similar findings have been seen from other studies around the globe $[20,21]$.

Since almost all of the participants agreed that it is important for them to get more information about antibiotics and were supportive of the establishment of courses at the university level to promote rational use of antibiotics, these are clear indicators that this group of graduates are seeking to study more about antibiotics.

As we found that there is no significant different in knowledge, perception and attitudes among final year pharmacy undergraduates from different universities in Sri Lanka, the academic curriculum is perhaps standardized among these universities specifically pharmacology, microbiology and clinical pharmacy modules related to antibiotics. All are based upon the same indicative syllabus.

Participants from urban Sri Lanka had a significantly positive perception ( $p=0.01)$ and attitudes $(p=0.036)$ towards antibiotics and ABR compared to that of rural participants. This may be due to easy access of information and availability of pharmacies and doctors to students in urban areas compared to rural.

As shown in our study, the knowledge of participants is predicting their perception (significant positive correlation) that may or may not lead to their behaviour. Hence correct knowledge about antibiotics and ABR are vital for future pharmacists to possess positive perception on antibiotics use and resistance.

\section{STRENGTH AND LIMITATION}

The main strengths of this study are the use of broadly representative samples with different cultural and geographical environments, thus, allowing us to generalise our findings, and that a $100 \%$ response rate from approached participants was achieved. However, the study also has several limitations. Self-reported measures are susceptible to memory bias and the social desirability effect. Events that are salient and recent are more likely to be remembered and reported compared to those that are less salient and more distant. The use of cross-sectional data also precludes any inferences about the directionality of effects.

\section{CONCLUSION}

This study reveals that final year pharmacy undergraduates' knowledge related to the appropriate use of antibiotic should be improved in Sri Lanka, hence this should be considered as a serious issue and immediate action is required to correct this before graduation.

This study indicated that specific in-depth education of university pharmacy students regarding antibiotics and their resistance is vital and may improve their knowledge and perception on rational usage of antibiotics, but knowledge may not always correlate with behaviour. Perhaps the pharmacology and clinical pharmacy modules of the B Pharm curriculum should also include considerable weight on antibiotics and antibiotics resistance. This could be achieved by incorporating more clinical practical components to their curriculum including clinical placement.

\section{ACKNOWLEDGEMENT}

The authors would like to thank all participated students from the University of Ruhuna, the University Sri Jayawardenapura, the
University of Colombo and the University of Jaffna for their contribution.

\section{AUTHORS CONTRIBUTION}

We certify this is our own original work, first author conducted the research, second author supervised the intervention and third author drafted the publication. All authors have contributed and agreed to the submission of this manuscript and that this work has not been submitted for publication elsewhere.

\section{CONFLICTS OF INTERESTS}

Declared none

\section{REFERENCES}

1. WHO, The global burden of disease, World Health Organization: Geneva; 2004. Available from: http://www.who.int/ healthinfo/global_burden_disease/2004_report_update/en.[La st accessed on 30 Aug 2017]

2. Costelloe C, Metcalfe C, Lovering A, Mant D, Hay AD. Effect of antibiotic prescribing in primary care on antimicrobial resistance in individual patients: systematic review and metaanalysis. Br Med J 2010;340:c2096.

3. WHO. Antimicrobial Resistance Global Report on Surveillance. WHO: Geneva; 2014. Available from: http://www.who.int/ drugresistance/documents/surveillancereport/en. [Last accessed on 30 Aug 2017]

4. Azevedo MM, Pinheiro C, Yaphe J, Baltazar F. Portuguese students' knowledge of antibiotics: a cross-sectional study of secondary school and university students in Braga. BMC Public Health 2009;9:359.

5. Igbeneghu OA. Knowledge and practices in the use of antibiotics among a group of Nigerian university students. Int J Infect Control 2013;9(i1):8.

6. Albrich WC, Monnet DL, Harbarth S. Antibiotic selection pressure and resistance in streptococcus pneumoniae and streptococcus pyogenes. Emerging Infect Dis 2004;10:514-7.

7. van de Sande-Bruinsma N, Grundmann H, Verloo D, Tiemersma E, Monen J, Goossens H, et al. Antimicrobial drug use and resistance in Europe. Emerging Infect Dis 2008;14:1722-30.

8. Goossens H, Ferech M, Vander Stichele R, Elseviers M. Outpatient antibiotic use in Europe and association with resistance: a crossnational database study. Lancet 2005;365:579-87.

9. McNulty CA, Nichols T, Boyle PJ, Woodhead M, Davey P. The English antibiotic awareness campaigns: did they change the public's knowledge of and attitudes to antibiotic use? J Antimicrob Chemother 2010;65:1526-33.

10. Hildreth $\mathrm{CJ}$, Burke $\mathrm{AE}$, Glass RM. Inappropriate use of antibiotics. JAMA 2009;302:816.

11. Gleckman RA. Selected issues in antibiotic resistance. Infect Med 2004;21:114-22.

12. WHO. Causes of death summary table. Word health organization: Genva; 2008. Available from: http://www.who.int/gho/mortality_burden_disease/causes_d eath_2008/en/. [Last accessed on 30 Aug 2017]

13. Wang J, Wang $\mathrm{P}$, Wang X, Zheng Y, Xiao Y. Use and prescription of antibiotics in primary health care settings in China. JAMA Internal Med 2014;174:1914-20.

14. Gulliford MC, Dregan A, Moore MV, Ashworth M, van Staa T, McCann G, et al. Continued high rates of antibiotic prescribing to adults with respiratory tract infection: survey of 568 UK general practices. Br Med J 2014;4:e006245.

15. Lee GC, Reveles KR, Attridge RT, Lawson KA, Mansi IA, Lewis JS, et al. Outpatient antibiotic prescribing in the United States: 2000 to 2010. BMC Med 2014;12:96.

16. Gaur AH, Hare ME, Shorr RI. Provider and practice characteristics associated with antibiotic use in children with presumed viral respiratory tract infections. Pediatrics 2005;115:635-41.

17. Erku DA, Surur AS, Gebresillassie BM. Extent of dispensing prescription-only medications without a prescription in community drug retail outlets in Addis Ababa, Ethiopia: a simulated-patient study. Drug Healthcare Patient Safety 2016;8:65-70. 
18. Wafula F. Availability and dispensing practices for antimalarials and antimicrobials in western Kenyan pharmacies. Pharm Reg Affairs 2013;2:8.

19. Bin Abdulhak AA, Al Tannir MA, Almansor MA, Almohaya MS, Onazi AS, Marei MA, et al. Non prescribed sale of antibiotics in Riyadh, Saudi Arabia: a cross sectional study. BMC Public Health 2011;11:538.

20. Parimi N, Pinto Pereira LM, Prabhakar P. Caregivers' practices, knowledge and beliefs of antibiotics in paediatric upper respiratory tract infections in Trinidad and Tobago: a crosssectional study. BMC Fam Pract 2004;5:28.

21. Srinivasan A, Song X, Richards A, Sinkowitz-Cochran R, Cardo D, Rand C. A survey of knowledge, attitudes, and beliefs of house staff physicians from various specialties concerning antimicrobial use and resistance. Arch Intern Med 2004;164:1451-6.

22. Lim VK, Cheong YM, Suleiman AB. Pattern of antibiotic usage in hospitals in Malaysia. Singapore Med J 1993;34:525-8.

23. Wolffers I. Drug information and sale practices in some pharmacies of Colombo, Sri Lanka. Soc Sci Med 1987;25:319-21.

24. Tomson G, Sterky G. Self-prescribing by way of pharmacies in three Asian developing countries. Lancet 1986;2:620-2.

25. Wickremasinghe SA, Bibile S. Pharmaceuticals management in Ceylon. Br Med J 1971;3:757-8.

26. Zawahir S, Lakmali N, Dhakshila N. Pharmacy practice in Sri Lanka, in fathelrahman a (Ed) pharmacy practice in developing countries: achievements and challenges. London, Academic Press; 2016. p. 516.

27. National Medicines Regulatory Authority (Sri Lanka). 2014. Available from: www.cdda.gov.lk/index.php? option=com contentandview $=$ articleandid $=50$ and Itemid=92andlang=en. [Last accessed on 20 Jul 2014]

28. Huang Y, Gu J, Zhang M, Ren Z, Yang W, Chen Y, et al. Knowledge, attitude and practice of antibiotics: a questionnaire study among 2500 Chinese students. BMC Medical Education 2013;13:163.

29. Ahmad A, Khan MU, Patel I, Maharaj S, Pandey S, Dhingra S. Knowledge, attitude and practice of B. Sc. Pharmacy students about antibiotics in Trinidad and Tobago. J Res Pharm Pract $2015 ; 4: 37-41$
30. Ganesh M, Sridevi SA, Paul CM. Antibiotic use among medical and para medical students: knowledge, attitude and its practice in a tertiary health care centre. Int J Sci Res 2014;3:4.

31. Buke C, Hosgor-Limoncu M, Ermertcan S, Ciceklioglu M, Tuncel $\mathrm{M}$, Köse $\mathrm{T}$, et al. Irrational use of antibiotics among university students. J Infect 2005;51:135-9.

32. Arroll B, Kenealy T. Are antibiotics effective for acute purulent rhinitis? Systematic review and meta-analysis of placebo controlled randomised trials. Br Med J 2006;333:279.

33. Dallas A, Magin P, Morgan S, Tapley A, Henderson K, Ball J, et al. Antibiotic prescribing for respiratory infections: a crosssectional analysis of the ReCEnT study exploring the habits of early-career doctors in primary care. Fam Pract 2015;32:49-55.

34. Kenealy T, Arroll B. Antibiotics for the common cold and acute purulent rhinitis. Cochrane Database Systematic Rev 2013;6:CD000247.

35. Huttner B, Goossens $\mathrm{H}$, Verheij $\mathrm{T}$, Harbarth S. CHAMP Consortium. Characteristics and outcomes of public campaigns aimed at improving the use of antibiotics in outpatients in highincome countries. Lancet Infect Dis 2010;10:17-31.

36. Dameh $M$, Norris P, Green PJ. New Zealand pharmacists' experiences, practices and views regarding antibiotic use without prescription. J Prim Health Care 2012;4:131-40.

37. Radyowijati A, Haak H. Improving antibiotic use in low-income countries: an overview of evidence on determinants. Soc Sci Med 2003;57:733-44

38. Awad AI, Aboud EA. Knowledge, attitude and practice towards antibiotic use among the public in kuwait. PLoS One 2015;10:e0117910.

39. Roque F, Soares S, Breitenfeld L, López-Durán A, Figueiras A, Herdeiro MT. Attitudes of community pharmacists to antibiotic dispensing and microbial resistance: a qualitative study in Portugal. Int J Clin Pharm 2013;35:417-24.

40. Chandrakanth P, Mohamed Saleem TS, Reddy MM, Rao MM. Assessment of public knowledge and attitude regarding antibiotic use in a tertiary care hospital. Asian J Pharm Clin Res 2016;118-22. Available from: https://innovareacademics.in/ journals/index.php/ajpcr/article/view/8152 [Last accessed on 30 Aug 2017]. 